\title{
PROPRANOLOL AS A SAFE AND EFFECTIVE TREATMENT OF THE INFANTILE HEAD AND NECK HEMANGIOMAS
}

\author{
By \\ Waleed Moneir, Hosam Elsisi and \\ Mohamed AbdElwahab \\ Trom \\ Otorhinolaryngology Departement, \\ Faculty of Medicine, Mansoura University.
}

\begin{abstract}
Objectives: To evaluate the efficacy of propranolol as a safe and effective line of treatment of different head and neck infantile hemangiomas.

Patients and methods: 13 cases of head and neck infantile hemangiomas with different localities. Propranolol is started at $0.5 \mathrm{mg} / \mathrm{kg} / \mathrm{d}$ in 3 divided doses for the first week. Then, the dose was increased to be $1 \mathrm{mg} / \mathrm{kg} / \mathrm{d}$ in 3 divided doses for the second week and finally doubled to be $2 \mathrm{mg} / \mathrm{kg} / \mathrm{d}$ in 3 divided doses which is the maintenance dose continued till the response become stationary in the form of achieving the maximum regression of the lesion or till reaching the involution phase
\end{abstract}

(age 12 months).

Results: Twelve cases showed no serious adverse effects of propranolol. Their mean age at the presentation was 9.33 (range 2 -22) months; their mean duration of administration of the drug at the maintenance dose was 6 (range 2 - 10) months and their mean follow up period after the stoppage of the drug was 7.23 (range 5-9) months. Only one case experienced recurrent attacks of asthmatiform bronchitis after 8 weeks of starting the treatment with very minimal regression of the lesion and did not complete the regimen. Twelve cases showed clinical improvement of the lesion in the form of reduction of the size of the lesion and change of the color from intense

MANSOURA MEDICAL JOURNAL 
red to purple with one of them developed re-growth of the lesion after stoppage of the treatment by 4 months later. No improvement was reported in one case.

Conclusion: Propranolol in a dose of $2 \mathrm{mg} / \mathrm{kg} / \mathrm{d}$ in 3 divided doses is a valuable line of treatment of different head and neck infantile hemangiomas with safe profile.

Key words: Beta-blockers, Infantile hemangioma, Propranolol, Corticosteroids, Subglottic.

\section{INTRODUCTION}

Infantile hemangiomas (IHs) are the most common infantile tumor, with a frequency of $4-10 \%$ (1). They are more common in Caucasians with predominance of the female in a ratio of $3: 1$. $60 \%$ of hemangiomas are located in the head and neck (2). Infantile hemangioma start to grow within the first 2 months of life that is continuing for the end of the first year of life followed by a period of more or less complete regression that is called involution phase. Fifty percentof lesions are completely involuted by the time the child is age 5 years and $70 \%$ by age 7 years (3).

Vol. 44, No. 1 \& 2 Jan. \& April, 2015
According to the site and size of IHs, they range from small asymptomatic benign lesions to large lifethreatening ones. Extensive $\mathrm{IH}$ could be a part of a syndrome including posterior cranial fossa malformations, hemangiomas, arterial lesions, coarctation of the aorta and/or other cardiac defects and eye abnormalities that is known as PHACE syndrome (1).

the past, the first line of treatment of $\mathrm{IH}$ is the oral corticosteroids which are unfortunately associated with many serious side effects with longstanding use $(2,4)$. Though interferon alfa and vincristine sulfate have significant toxic effects, they could be used in cases of extensive lifethreatening hemangiomas not responding to corticosteroids $(5,6)$.

Le'aute'-Labrèze and others, in 2008 , accidentally reported rapid regression of hemangiomas in 2 children were given propranolol as a treatment of irrelevant cardiopulmonary conditions (7). Following supporting reports were achieved about the role of propranolol in the management of $\mathrm{IH}$ in the head and neck as laryngotracheal ones (8). Based 
Waleed Moneir et al ...

on the results of combined grayscale and color Doppler ultrasound imaging, the role of propranolol in management of IHs could be explained by reducing vessel density (9). There is no case of life-threatening complications or even serious side effects in infants with cardiac problems administered propranolol for a long time. So, propranolol has a welldocumented safety and side effect profile (10). Many side effects of propranolol were reported rarely and at higher doses more than $2 \mathrm{mg} / \mathrm{kg} /$ day as bradycardia, hypotension, hypoglycemia, rash, gastrointestinal discomfort, fatigue and bronchospasm $(11,12)$. Here, we report the efficacy of propranolol in management of 13 cases of different head and neck IHs and assess the safety profile of the drug.

\section{PATIENTS AND METHODS}

This study is a prospective clinical series study that was conducted on randomly selected thirteen cases that were children with head and neck extracranial infantile hemangiomas. All of the cases were fulfilled the natural history of the infantile hemangioma and followed up at the outpatient clinic of the otorhinolaryn- gology department of Mansoura University Hospital (MUH) in the period from August 2012 till April 2014. Three of the cases were presented by stridor resulted in their admission to the otorhinolaryngology department of MUH for performing urgent tracheotomy as a life saving procedure then direct laryngoscopy (DL) by endoscopic evaluation was performed to each under general anesthesia explaining the cause of the stridor by the presence of subglottic hemangioma. One of the previous three cases was combined with left hemifacial hemangioma. The remaining nine cases were presented by many complaints as aesthetic problem or functional risks according to the sites of the hemangiomas as shown in table 1.One case did not complete the regimen because of developing serious adverse effect.Two of the cases had already received oral prednisone for two to three months with moderate improvement then relapse occurred after four months. Surgical excision of the lesion was performed in one case with recurrence after seven months. Intralesional local injection of corticosteroids was performed in one case with no improvement. All of the cases

MANSOURA MEDICAL JOURNAL 


\section{PROPRANOLOL AS A SAFE AND EFFECTIVE etc...}

were documented by either photography or recording the $\mathrm{DL}$ procedures of the cases suffered from subglottic hemangiomas on CDs. Informed consents were obtained from the legal guardians of the children (almost the parents). Before starting the regimen, we arranged by personal contact for a pediatrician at the locality of each patient to be easily accessible during the period of administration of the drug. The pediatricians ruled out treatment contraindications with electrocardiography (ECG) and echocardiography $(E C H O)$ hence they approved the regimen and plan to follow up the clinical symptoms and possible side effects as he do with his patients prescribed propranolol for another indications. We excluded the presence of internal organs hemangioma by asking for abdominal U/S. Also, the presence of segmental hemangioma with its accompanying PHACE findings was excluded in the case of massive facial hemangioma. In the case of eye lids lesions, an ophthalmologist was consulted to report any other eye lesions or affection of the vision. Patients included in this study were already diagnosed as infantile hemangiomas according to their nat- ural history and fullfilled the following criteria: (1) No contraindications of propranolol; (2) No intracranial manifested lesions; (3) No internal organs hemangiomas; (4) No PHACE findings in suspicious cases to be segmental hemangiomas.

\section{The regimen:}

Baseline vital signs (pulse and blood pressure) were measured and reported by the pediatrician before starting the regimen. Propranolol 10 $\mathrm{mg}$ oral tablet (Inderal $10 \mathrm{mg}$ oral tablet) was dissolved in $10 \mathrm{ml}$ of distilled water then taken orally by scored spoon $(1 \mathrm{mg} / \mathrm{ml})$ under the following regimen:

We followed the regimen reported by Fuchsmann and others, in 2011, (13). Propranolol was started at 0.5 $\mathrm{mg} / \mathrm{kg} / \mathrm{d}$ in 3 divided doses for the first week. Then, the dose was increased to be $1 \mathrm{mg} / \mathrm{kg} / \mathrm{d}$ in 3 divided doses for the second week and finally doubled to be $2 \mathrm{mg} / \mathrm{kg} / \mathrm{d}$ in 3 divided doses which is the maintenance dose. At the start of the treatment and at each time of increase of the dose, the cases were given the drug in the outpatient clinic with 2-hour follow-up and with visit to the pedia- 
Waleed Moneir et al ...

trician on the same day to assess the drug tolerance by measuring pulse rate and blood pressure. Parents were advised to care about the feeding of the child because of hypoglycemia risk. They were also informed about the clinical signs of the possible side effects of the drug as hypotension, bradycardia, hypoglycemia, bronchospasm andsleep disturbances. Site of the lesion, complaint, age of the child at the start ofthe treatment, duration of the treatment, clinical improvement and recurrence were reported. The three cases with subglottic hemangioma were examined endoscopically under GA at the start of the treatment and after 4 weeks of the start of the maintenance dose. The cutaneous lesions were evaluated 2 weeks after the onset of the treatment then monthly by clinical evaluation. Parents were asked to send photographs of the cutaneous hemangiomas of their children as possible as they can weekly from the onset of the treatment. The response to propranolol was evaluated subjectively by one reviewer (the corresponding author) and based mainly on change in lesion size (improvement $=\geq 50 \%$ decrease in size) and color. The maintenance dose was given till the response became stationary in the form of achieving the maximum regression of the lesion or till reaching the involution phase (age 12 months) in the cases with considerable response before this age then reduced weekly by the same manner of the increase the dose at the start of the treatment (13).

\section{RESULTS}

Thirteen cases ( 7 females and 6 males) fulfilled the inclusion criteria of the study but one of them experienced recurrent attacks of asthmatiform bronchitis after 8 weeks of starting the treatment with very minimal regression of the lesion. Hence, we wisely decided to withdraw the drug then stop it. As regard to the other twelve cases, the mean age at the presentation was 9.33 (range $2-22$ ) months, the mean duration of administration of the drug at the maintenance dose was 6 (range 2 - 10) months and the mean follow up period after the stoppage of the drug was 7.23 (range $5-9$ ) months. Except one case, all the cases showed clinical improvement of the lesion in the form of reduction of the size of the lesion and change of the color

MANSOURA MEDICAL JOURNAL 
from intense red to purple. One case developed re-growth of the lesion after stoppage of the treatment by 4 months later. Mild bradycardia and hypotension were reported in the first month of the treatment without symptoms that were considered as drug effects rather than complications and did not require cessation of the drug.

Table (1): sites, complaints, age, duration of the treatment, response and relapses details of the 13 cases.

\begin{tabular}{|c|c|c|c|c|c|c|}
\hline $\begin{array}{c}\text { Patient } \\
\text { No. }\end{array}$ & $\begin{array}{c}\text { Site of } \\
\text { the lesion }\end{array}$ & Complaint & $\begin{array}{l}\text { Age in m. } \\
\text { at the } \\
\text { onset of } \\
\text { treatment }\end{array}$ & $\begin{array}{c}\text { Duration of } \\
\text { maintenance } \\
\text { dose in } \mathbf{m} .\end{array}$ & Response & $\begin{array}{c}\text { Recurrence } \\
\text { after } \\
\text { stopping } \\
\text { the drug }\end{array}$ \\
\hline 1 & $\begin{array}{l}\text { Subglottic } \\
\text { and left } \\
\text { hemifacial }\end{array}$ & $\begin{array}{l}\text { Respiratory } \\
\text { distress } \\
\text { (stridor) and } \\
\text { cosmosis }\end{array}$ & 6 & 6 & $\begin{array}{c}\text { Improvement } \\
\text { of the } \\
\text { subglottic } \\
\text { lesion with } \\
\text { improvement } \\
\text { to a lesser } \\
\text { extent of the } \\
\text { skin lesion }\end{array}$ & No \\
\hline 2 & Subglottic & $\begin{array}{c}\text { Respiratory } \\
\text { distress } \\
\text { (stridor) }\end{array}$ & 2 & 10 & Improvement & No \\
\hline 3 & Subglottic & $\begin{array}{c}\text { Respiratory } \\
\text { distress } \\
\text { (stridor) }\end{array}$ & 3 & $\begin{array}{c}6 \text { and } \\
\text { continuing }\end{array}$ & Improvement & - \\
\hline 4 & Nasal tip & Cosmosis & 14 & 6 & No response & - \\
\hline 5 & Nasal tip & Cosmosis & 8 & 4 & Improvement & No \\
\hline 6 & Upper lip & Cosmosis & 16 & 7 & Improvement & No \\
\hline 7 & $\begin{array}{l}\text { Lower lip } \\
\text { and chin }\end{array}$ & Cosmosis & 12 & 4 & Improvement & No \\
\hline 8 & $\begin{array}{c}\text { Chin and } \\
\text { neck }\end{array}$ & Cosmosis & 10 & 6 & Improvement & $\begin{array}{l}\text { Recurrence } \\
\text { after } 4 \mathrm{~m} \text {. }\end{array}$ \\
\hline 9 & $\begin{array}{c}\text { Parotid } \\
\text { region }\end{array}$ & Cosmosis & 22 & 4 & Improvement & No \\
\hline 10 & $\begin{array}{l}\text { Parotid } \\
\text { region } \\
\text { and neck }\end{array}$ & Cosmosis & 6 & 6 & Improvement & No \\
\hline 11 & $\begin{array}{c}\text { Upper eye } \\
\text { lid }\end{array}$ & $\begin{array}{c}\text { Visual } \\
\text { impairment } \\
\text { and } \\
\text { cosmosis }\end{array}$ & 5 & 5 & Improvement & No \\
\hline 12 & $\begin{array}{l}\text { Upper eye } \\
\text { lid and } \\
\text { forehead }\end{array}$ & $\begin{array}{c}\text { Visual } \\
\text { impairment } \\
\text { and } \\
\text { cosmosis } \\
\end{array}$ & 8 & 8 & Improvement & No \\
\hline 13 & $\begin{array}{l}\text { Chin and } \\
\text { neck }\end{array}$ & Cosmosis & 10 & 2 & \multicolumn{2}{|c|}{$\begin{array}{l}\text { Stopping the drug as } \\
\text { developing serious side } \\
\text { effect of the drug without } \\
\text { response }\end{array}$} \\
\hline
\end{tabular}

Vol. 44, No. 1 \& 2 Jan. \& April, 2015 

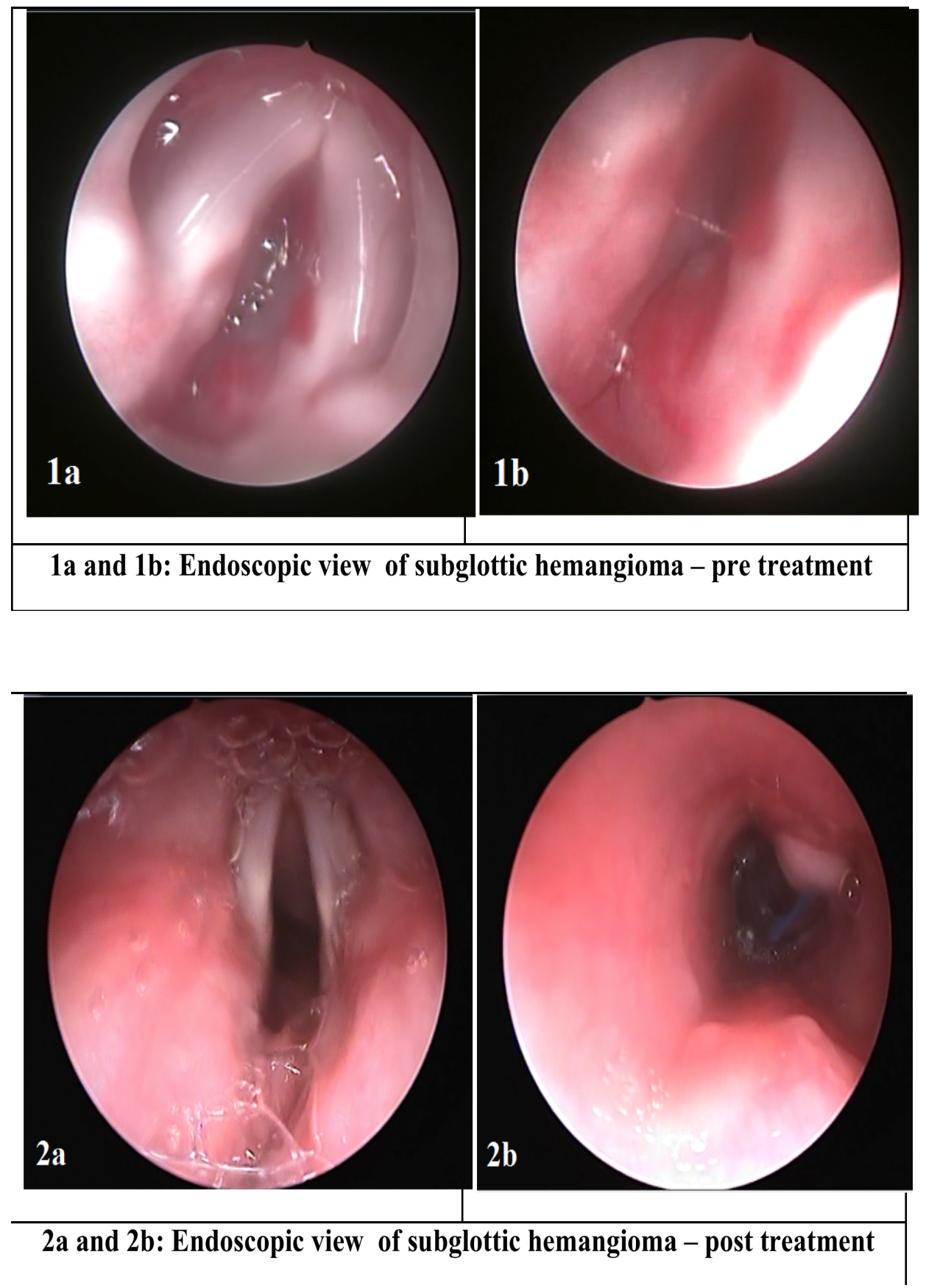

MANSOURA MEDICAL JOURNAL 

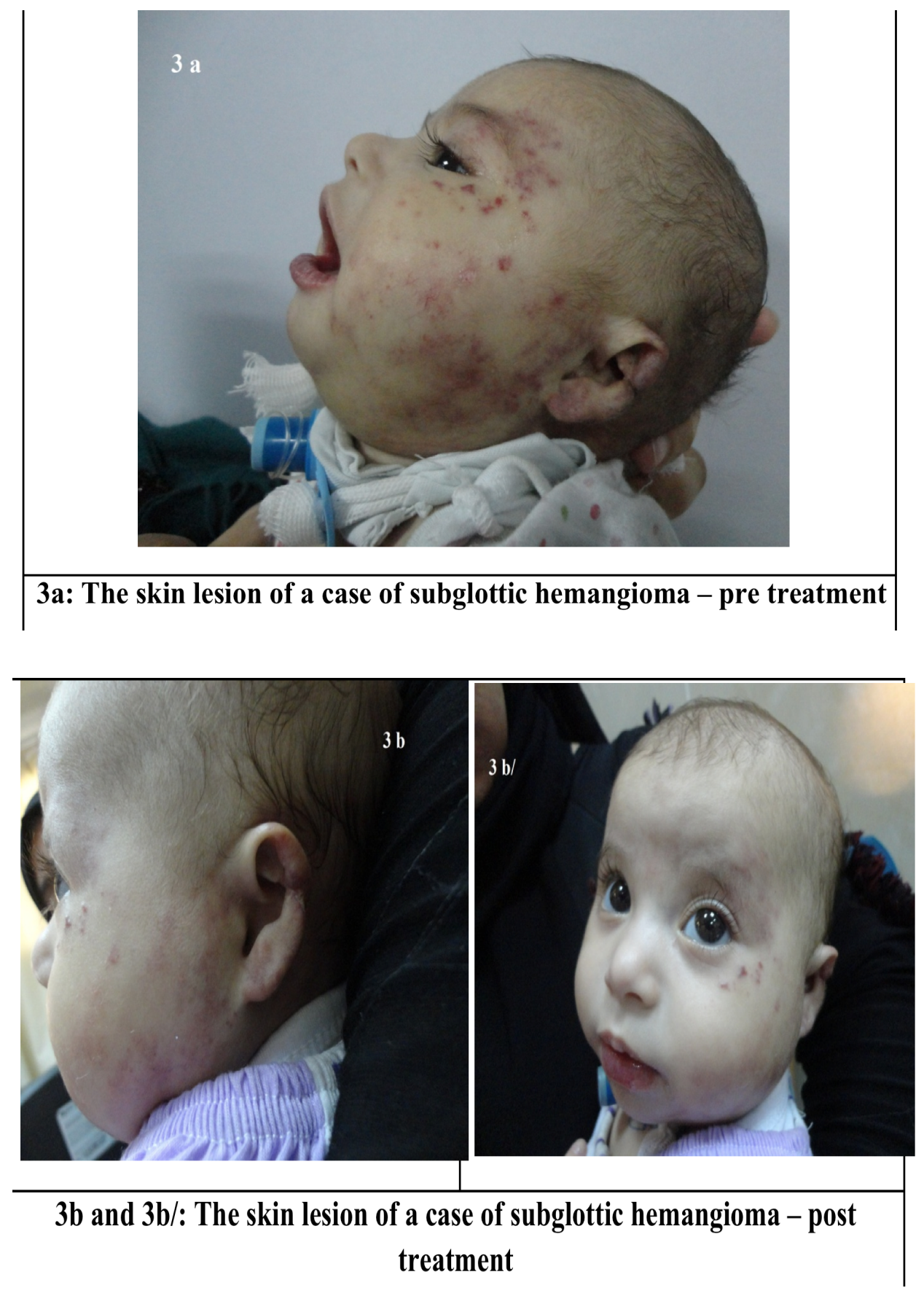

Vol. 44, No. 1 \& 2 Jan. \& April, 2015 


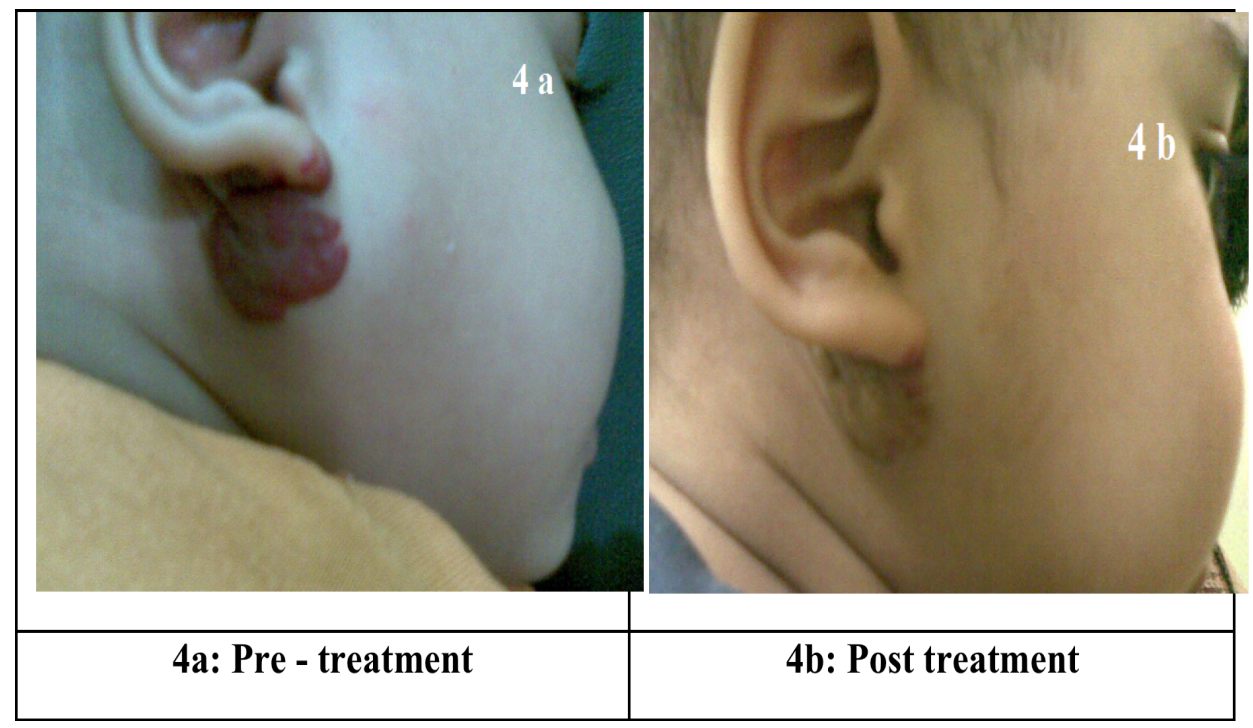

\section{DISCUSSION}

IHs are the most common benign tumor of infancy with expected course of rapid growth begins at the second month of life and continues till the end of the first year of life. Then, they regress in a period called involution phase and lasting for months or years (14). Since the accidental discovery of the efficacy of propranolol in treating infantile hemangiomas by Le'aute'-Labrèze and others (7), many reports supported this finding $(8,15)$. Like the previous researches, we stated the valuable efficacy of propranolol which is a beta-blocker in treatment of different head and neck IHs with a high safety profile. Our study was conducted to 13 cases of children with different localities head and neck IHs treated with propranolol. We found that 11 cases responded dramatically within the first month in the form of reduction of the size of the lesion. Particularly in the cases of the skin ones, notable changes of the lesion were reported in the form of becoming flat and changing the color from intense red to purple. Many reports depended on ultrasonography to assess the improvement achieved to IHs after the use of beta-blockers $(16,17)$. Clinical evaluation of hemangiomas by assessing their size, shape and color is relevant and accurate al- 
though subjective. Ultrasonographic measurements are not mandatory for skin lesions (13). The ideal duration of administration of propranolol to decrease the possibility of relapse and to get maximum effect on hemangiomas with least side effects is a conflicting matter. Sans and others, in 2011, reported relapses occurred in many cases after stopping propranolol before age 11 months (17). Denoyelle and others, in 2009, succeeded to prevent relapse of the lesion by continuing propranolol in cases of laryngeal hemangiomas until the age of 18 months (8). In our study, though almost of the cases that stop propranolol before age 18 month did not relapse, relapse occurred in one case with $\mathrm{IH}$ of the chin and neck that started propranolol at age of 10 month and continued on it for 6 months (age of 16 month) till getting maximum regression. The relapse occurred 4 months after cessation of the drug that is supporting the finding of the team of Denoyelle stating that administration of propranolol till age of 18 month eliminates the possibility of recurrence. Almost of the previous reports stated the safety profile of the use of propranolol dosages of $2 \mathrm{mg} / \mathrm{kg} / \mathrm{d}$

Vol. 44, No. 1 \& 2 Jan. \& April, 2015 that is sufficient to have a maximal effect on hemangiomas. In our series, we support the same concept but with restrict and close follow up by an efficient pediatrician to manage the possible side effects as one of our cases developed asthmatiform bronchitis after 8 weeks of starting the treatment.

\section{CONCLUSION}

Propranolol in a dose of $2 \mathrm{mg} / \mathrm{kg} /$ $\mathrm{d}$ in 3 divided doses is a valuable line of treatment of different head and neck infantile hemangiomas with safe profile and close follow up by an efficient pediatrician is mandatory. The drug must be continued till the age of 18 month to prevent relapse.

\section{REFERENCES}

1 - Frieden IJ, Haggstrom AN, Drolet BA, et al. (2005) : Infantile hemangiomas: current knowledge, future directions. Proceedings of a Research Workshop on Infantile Hemangiomas; 2005 April 7-9; Bethesda, Maryland.Pediatric Dermatol.; 22(5):383-406.

\section{2 - Le'aute'-Labrèze $C$ and Taieb A}


(2008) : Efficacy of betablockers in infantile haemangiomas: the physiopathological significance and therapeutic consequences. Ann. Dermatol. Venerol.; 135: 860-862.

\section{3 - Margileth AM and Museles M} (1965) : Cutaneous hemangiomas in children: diagnosis and conservative management. JAMA.; 194(5): 523-526.

4 - George ME, Sharma V, Jacobson J, et al. (2004) : Adverse effects of systemic glucocorticosteroid therapy in infants with hemangiomas. Arch Dermatol.; 140 (8): 963-969.

5 - Ezekowitz RA, Mulliken JB, Folkman J (1992) : Interferon alfa-2a therapy for lifethreatening hemangiomas of infancy. New England $\mathrm{J}$ of Medicine; 326 (22): 1456-1463.

\section{6 -Enjolras O, Brevière GM, Roger} G, et al. (2004) : Vincristine treatment for function- and life-threatening infantile hemangioma. Arch $\mathrm{Pe}$ diatr.; 11(2):99-107.

7- Le'aute'-Labrèze $C$, Dumas de la RoqueE, Hubiche $T$, et al. (2008) : Propranolol for severe hemangiomas of infancy. New England $\mathrm{J}$ of Medicine; 358 (24): 26492651.

8 - Denoyelle F, Leboulanger N, Enjolras O, et al. (2009) : Role of propranolol in the therapeutic strategy of infantile laryngotrachealhemangioma. Int J PediatrOtorhinolaryngol.; (8):1168-1172.

9 - Bingham MM, Saltzman B, Vo NJ, et al. (2012) : Propranolol reduces infantile hemangioma volume andvessel density. Otolaryngol Head Neck Surg.; 147:338344.

10 -Buckmiller L, Dyamenahalli U, Richter GT (2009) : Propranolol for airway hemangiomas : case report of novel treatment, Laryngo- 
scope.; 119(10): 2051- Prospectivestudy of infan2054.

tile hemangiomas: clinical characteristics predicting

11 -Helfand M, Peterson K, Dana T complications and treat(2007) : Drug Class Review on Beta Adrenergic ment. Pediatrics.;

Blockers, http:// www.ohsu.edu/ 118:882-887.

drugeffectiveness/reports/ final.cfm.

12 -Siegfried EC, Keenan WJ, AIJureidini S (2008) : More on propranolol for haemangiomasof infancy. New England $\mathrm{J}$ of Medicine; 359: 2846-2847.

13 - Fuchsmann C, Quintal M, Giguere C, et al. (2011) : Propranolol as first-line treatment of head and neck hemangiomas. Arch Otolaryngol Head Neck Surg.; 137(5):471-478.

14 - Haggstrom AN, Drolet BA, Baselga $E$, et al. (2006) :

15 - Truong MT, Chang KW, Berk DR, et al. (2010) : Propranolol for the treatment of a life threatening subglottic and mediastinal infantilehemangioma. J Pediatr.; 156 (2):335-338.

16 -Michel JL and Patural H (2009) : Response to oral propranolol therapy for ulcerated hemangiomasin infancy. Arch Pediatr.; 16(12):15651568.

17 - Sans V, de la Roque ED, Berge J, et al. (2009) : Propranolol for severe infantile hemangiomas: follow-up report. Pediatrics; 24(3):e423-e431. 